\title{
Persona postamputada portadora de dolor de miembro fantasma: Dolor y cuerpo
}

\author{
María Cristina Ochoa Estrada,* Sebastián Bustamante Edquen**
}

\begin{abstract}
RESUMEN
La presente investigación se plantea a través de un abordaje descriptivo-cualitativo. El objetivo fue describir y analizar "lo cotidiano" de la persona postamputada con dolor de miembro fantasma en el estado de Durango, México. El método utilizado fue exploratorio-descriptivo, y como técnica se empleó la entrevista semiestructurada. Los sujetos seleccionados provenían de seis municipios del estado de Durango, México. Debido a la naturaleza del estudio, participaron cuatro personas que al ser amputadas debutaron con dolor de miembro fantasma. El soporte teórico de la presente investigación está integrado y complementado por el pensamiento respecto a lo cotidiano de Maffesoli (1998), ${ }^{1}$ la corporalidad de David Le Breton (2002) ${ }^{2}$ y el dolor de David Le Breton (1999). ${ }^{3}$ Se construyeron tres categorías: 1. Lo corporal, 2. El tiempo y movimiento y 3 . Trabajo y ocio.
\end{abstract}

Palabras clave: Cotidiano, paciente amputado, dolor de miembro fantasma.

\section{Person carrying postamputed phantom limb pain: Pain and body}

\begin{abstract}
This research is descriptive-qualitative approach, the aim was to describe and analyze the daily life of the person carrying postamputed phantom limb pain on state of Durango in Mexico. The method used was exploratory-descriptive, semistructured interview technique. The key informants selected as acting subjects, came from six municipalities of Durango' State, Mexico. Due to the nature of this study, participated four people being amputated debut with Phantom Limb Pain. The theoretical support of this research is integrated and complemented by thinking about the daily life of Maffesoli (1998), the corporeality of David Le Breton (2002) and the pain of David Le Breton (1999). They built three categories: 1. The body, 2. Time and movement, 3. Work and Leisure.
\end{abstract}

Key words: Daily, patient amputed, phantom limb pain.

\section{INTRODUCCIÓN}

$\mathrm{L}$ a amputación es, sin duda, la más antigua técnica quirúrgica; está indicada siempre que la lesión traumática haya afectado de una manera irreparable la utilidad de la extremidad. Esencialmente hablamos de lesiones de tal gravedad que determinan la imposibilidad de recuperación de la función de la extremidad hasta un nivel de rendimiento igual o superior al de la prótesis de amputación. ${ }^{4}$

El dolor es una experiencia sensorial y emocional desagradable asociado con una lesión tisular real o potencial, que se describe en función de dicha lesión. ${ }^{5}$

* Maestra en Administración de la Atención en Enfermería. Facultad de Enfermería y Obstetricia. Universidad Juárez del Estado de Durango. ** Doctor en Ciencias de Enfermería. Profesor Principal de la Facultad de Enfermería. Universidad Nacional de Trujillo, Perú.

Correspondencia: María Cristina Ochoa Estrada

Celular: 618 1891301.E-mail: cristys8@hotmail.com cristy8@ujed.mx

Este artículo puede ser consultado en versión completa en http://www.medigraphic.com/enfermerianeurologica 
La aparición del dolor de miembro fantasma constituye la consecuencia más impresionante a la que se enfrentan los pacientes que sufren una amputación. Aunque, en términos generales, este fenómeno hace referencia a la percepción real y viva del miembro amputado que se experimenta después de la amputación de una extremidad, el concepto fantasma puede ser empleado para la percepción de cualquier otra parte corporal amputada. La fuerte intensidad y la detallada descripción de las sensaciones fantasmas que refieren las personas afectadas, sugieren que deben existir ciertos mecanismos fisiológicos que constituyen la base neurobiológica del miembro fantasma. Según la Asociación Internacional para el Estudio del Dolor (IASP, por sus siglas en inglés) se ha de distinguir entre sensaciones dolorosas y no dolorosas en el miembro fantasma y en el muñón. De acuerdo con diversos estudios, entre el 70 y $100 \%$ de los pacientes amputados afirmaron experimentar con nitidez sensaciones exteroceptivas no dolorosas (por ejemplo, picor, la forma y movimiento de los dedos, etcétera), procedentes del miembro fantasma. Además, para el $60-85 \%$ de estos pacientes estas sensaciones son dolorosas. Los adjetivos usados para describir este dolor suelen ser los siguientes: sensación exagerada de hormigueo, picazón, ardor, presión, calambres, prurito y entumecimiento. ${ }^{6}$

La filosofía de la identidad del cuerpo implica, al menos, dos aspectos. El primero supone la posibilidad de percibir y describir la permanencia del mismo, lo que no todas las culturas han logrado. El segundo, implicado en la filosofía de la identidad del cuerpo humano, se halla en ubicarlo no sólo en un tiempo y en un espacio, sino postular su identidad porque es posible concebir su permanencia. ${ }^{7}$

Lo mencionado anteriormente tiene relación con los ámbitos de la vida cotidiana, puesto que la Organización Mundial de la Salud afirma que las personas tienen oportunidad de mantenerse físicamente activas en cuatro sectores principales de la vida diaria: el primero, el trabajo, especialmente si éste entraña una actividad manual; el segundo, el trasporte, como caminar o ir en bicicleta al trabajo; el tercero, las tareas domésticas, por ejemplo, ocuparse de los quehaceres de la casa. Por último, el tiempo libre u ocio, como participar en actividades físicas y deportivas, generando cambios en nuestra vida presente y futura.

La escasa investigación dentro del área de la enfermería en torno al dolor de miembro fantasma en personas postamputadas constituye una puerta para el desarrollo de nuevos procesos de intervención, en los cuales se pueda mejorar la calidad de vida de este tipo de personas. Por ello, el interés por los conocimientos que este documento pueda generar para el quehacer profesional.

\section{REFERENCIAL METODOLÓGICO}

El abordaje cualitativo-descriptivo ${ }^{8}$ se consideró apropiado para el desarrollo de este estudio, ya que permitió interpretar "lo cotidiano" de la persona postamputada portadora de dolor en miembro fantasma. El escenario de estudio se desarrolló en seis municipios del estado de Durango, México. Los sujetos de investigación fueron personas que presentaban o manifestaban la patología de miembro fantasma, aquéllas con amputación en miembros inferiores y superiores, y personas con amputación a nivel supracondílea, infracondílea y transmetatarsiana, géneros masculino y femenino, con edades de 18 a 35 años; también personas con amputación de algún miembro de dos años o menos de evolución.

La técnica para la recolección de datos fue la entrevista semiestructurada, de naturaleza individual, plasmada en un formulario preestablecido con preguntas directas, ${ }^{9}$ las cuales se dividen en dos partes: la primera, caracteriza a los sujetos de la investigación, y en la segunda, las preguntas están relacionadas con el sujeto de estudio. Para reunir la información, se realizó previamente el reconocimiento de los participantes en el estudio mediante visitas planificadas a sus domicilios; se entrevistaron individualmente y se registraron en grabadora; se obtuvo con anterioridad el consentimiento del participante y se realizó en horarios disponibles y en los domicilios de cada uno. Realizamos la lectura de los discursos que fueron transcritos textualmente. Cada discurso se analizó para luego construir las categorías referidas a las bases teóricas. El periodo de recolección de datos fue de abril a agosto de 2011. Procedimos al análisis temático de la información. ${ }^{10}$ Para la operacionalización del análisis se siguieron básicamente tres etapas: preanálisis, exploración del material y tratamiento e interpretación de los resultados..$^{10}$ Como resultado del análisis temático se identificaron cuatro categorías empíricas, con base en tres entrevistas ya analizadas, siguiendo la orientación de los autores que constituyen el marco teórico. Estas categorías fueron: 1. Lo corporal, 2. El tiempo y movimiento y 3. Trabajo y ocio. Este artículo versa sobre los resultados preliminares de la primera categoría de la investigación de tesis doctoral.

\section{LO CORPORAL}

El cuerpo es nuestra expresión de "ser en el mundo". Es lo que nos proporciona un determinado lugar y la facultad de estar vivos. El cuerpo, incluso, nos puede otorgar un estatus social. ${ }^{11}$

Freud (1923) sugería que del cuerpo y de la superficie corporal parten percepciones hacia la conciencia, tanto internas 
como externas, y estímulos de todos los tipos: nociceptivos, enteroceptivos, propioceptivos, así como toda la amplia gama de sensaciones sensorio-motrices. El dolor también desempeña una relevante función en esta toma de conciencia corporal, ya que a través de las enfermedades y su dolor adquirimos consciencia de nuestros órganos internos y de su estado. ${ }^{12}$ Mediante este conjunto de estímulos y sensaciones polimorfos, llegamos a obtener una representación general del propio cuerpo. Esta representación es la síntesis de: 1. La aportación sensorial, sensual, táctil y visual del propio cuerpo; 2. De la imagen postural del cuerpo en movimiento, operando sobre lo que le rodea, adquiriendo experiencia de las capacidades motrices mediante la manipulación del medio, obteniendo pruebas de su agilidad, coordinación, habilidad, fuerza, etc., y 3. De la figuración estética mediante la identificación de elementos tales como la voz, el olor del propio cuerpo, etcétera. ${ }^{13}$

Esta percepción y personalización del cuerpo es un complejo de vida y de cuidado de vida en la persona que ha sido amputada, ya que el dolor induce a la renuncia parcial de uno mismo. Se suelen presentar actos (muecas, sollozos, etc.), palabras (juramentos, quejas, etc.) o sentimientos (como la muerte) que rompen las reglas de comportamiento habitual, o bien, el individuo se retrae en sí mismo para afrontar su mal sin debilitar su energía:

"El estar sentado es incómodo, me desespera, me causa dolor en el pecho y en mis pies, aunque ya no los tengo, duelen mucho por las tardes" (P-1).

"No puedo caminar, me siento incómodo, me duele y desespero con ganas de llorar" (P-1).

"El dolor no es nada bueno en mi cuerpo, [te] sientes morir" (P-1).

"Creo que yo soy el problema, mas cuando no controlo el dolor, estoy intranquilo, siento que me duele y me quema al mismo tiempo" (P-2).

"Es feo vivir con el dolor, y más como yo estoy; sientes dolor en una parte de tu cuerpo que ya no tienes y eso me llena de rabia" (P-2).

"No se lo deseo a nadie, en un inicio era insoportable. Ahora lo manejo con tratamiento médico, sólo me molesta en ocasiones" (P-3).

"El dolor que me provoca después de la amputación es feo, molesto, sientes desesperación, y más cuando no logras suprimirlo con nada; hagas lo que hagas, ahí está presente; aunque a veces tengas que fingir que no sientes nada, no se va, y así, aunque trates de ignorarlo" (P-4).

"Qué le puedo contar de mi cuerpo: ya no es el mismo, la gente ya no te mira igual, te ven diferente, te tratan como un discapacitado, y yo no me considero serlo, claro que no, no lo soy" (P-4).
Los discursos anteriores evidencian que el dolor de miembro fantasma en la persona postamputada no se limita con alterar la relación de la persona con su cuerpo; se expande más allá, anticipa los gestos, atraviesa los pensamientos y contamina la totalidad de la relación con el mundo. Rompe las amarras que ataban al individuo a sus actividades cotidianas, hace difícil su relación con los más próximos, elimina o disminuye en el hombre el placer de vivir.

La corporalidad es más que la materialidad del cuerpo que la suma de sus partes; es el contenido en todas las dimensiones humanas. No es algo objetivo, listo y acabado, sino un proceso continuo de redefiniciones; es el rescate del cuerpo, el dejar fluir, hablar, conversar, vivir, escuchar, permitir al cuerpo ser el actor principal, viéndolo en su dimensión realmente humana. Corporalidad es existir, es mi, su y nuestra historia. La compresión de la corporalidad es fundamental para un abordaje más humano en enfermería. ${ }^{14}$

En ese sentido, el cuerpo tiene presencia en el mundo, al hablar, conversar, vivir, escuchar, complementándolo con intercambios corporales, posturas y emociones de la persona. Gracias al cuerpo, a su disposición y acción en situaciones determinadas, el espacio en el que se mueve se convierte en un sitio roturado por nuestras acciones pasadas, presentes y futuras:

"Mi cuerpo es mío, es lo único que me queda, no es normal; [pero] es lo único que me queda, sin piernas, sin movimientos" (P-1).

"Me siento incompleto, feo, ya no sirvo, no funciono" (P-1). "Mi cuerpo, qué le diré de mi cuerpo, pues véame usted cómo estoy, incompleto, ya no te funciona igual y estás mocho" (P-2).

"Me siento incompleto, inservible, ahora dependo de mi familia hasta para que me limpien después de mis necesidades corporales" (P-2).

"Estoy mutilada, inválida" (P-3).

"Aunque no está completo lo quiero mucho, me embaracé de mi hijo. Veo mi cuerpo como si fuera el de un bebe" (P-3). "Físicamente no me siento completo, es difícil adaptarte a vivir como estoy yo, sólo con una pierna que te disminuye como persona" (P-4).

Con lo anterior, se evidencia cómo la expresión corporal en la persona postamputada se puede modular socialmente, aunque siempre se le designa según el propio estilo del individuo; los demás contribuyen a dibujar los contornos de su universo y darle al cuerpo el relieve social que necesita; el cuerpo ofrece la posibilidad de construirse como actor de la sociedad a la que se pertenece. Dentro de una comunidad, todas las manifestaciones sociales de la persona postam- 
putada son virtualmente significantes para sus miembros. Únicamente tienen sentido en relación con el conjunto de los datos simbólicos del grupo social. No existe nada natural en un gesto o en una sensación.

\section{CONSIDERACIONES FINALES}

En este apartado no se pretende expresar conclusión alguna; sin embargo, considero pertinente realizar algunas reflexiones sobre el tema estudiado: lo cotidiano de las personas postamputadas portadoras de dolor de miembro fantasma; las entrevistas fueron valiosas y significativas en contenido, lo que contribuyó al aprendizaje a lo largo de este proceso. En los discursos de las personas actuantes se reveló el vivir con dolor en relación con una parte del cuerpo que ya no tiene. Se describe cómo la persona construye su vivir diario, cargada de sentimientos.

Perder una parte del cuerpo es desconcertante y doloroso, puesto que ha dejado de ser un cuerpo completo para convertirse en algo extraño; se decepcionan y disgustan a causa de su nuevo aspecto físico, muy alejado del discurso social del cuerpo que se tiene en nuestra cultura. ${ }^{15}$

La persona postamputada se percibe como incompleta, impotente ante la situación que está sufriendo, la cual se manifiesta por dolor, miedo, angustia, y debe adaptarse a nuevos modos de vida, traspasando barreras para dirigirse a sus posibilidades reales, que en no pocas ocasiones están llenas de complejidad.

Entender el sufrimiento en las personas postamputadas portadoras de dolor de miembro fantasma resulta verdaderamente crucial para que el profesional de enfermería ponga en práctica actividades de modo completo y sea más efectivo. Mirar a este tipo de pacientes como un ser holístico permitirá un cuidado dirigido a su singular personalidad y a la particularidad de sus experiencias vividas.

El profesional de enfermería requiere demostrar conocimientos científicos, tecnológicos, humanísticos, experiencias personales, arte, ánimo, afecto y un pensamiento crítico-reflexivo, puesto que su objetivo es el de cuidar, actividad que debe ser realizada considerando el vivir de una persona como individual holístico.

\section{BIBLIOGRAFÍA}

1. Tedesco JC. Paradigmas do cotidiano. Introduçáo à constituiçào de um campo de analise social. Editora Da UNISC; 1999.

2. Le Breton D. La sociología del cuerpo. Buenos Aires: Nueva Visión; 2002.

3. Le Breton D. Antropología del dolor. París: Editions Metailié; 1999.

4. Serra G. El paciente amputado. Editorial Springer Ibérica; 2001.

5. PLM. Guía de manejo del Dolor. México; 2010.

6. López TJ, Blanco T, Ortiz P. Dolor del miembro fantasma. En: Serra CJ. Tratado de dolor neurótico. Buenos Aires-Madrid: Panamericana; 2006.

7. Daros WR. En búsqueda de la identidad personal. Problemática filosófica sobre construcción del "yo" y su educación. Universidad del Centro Educativo Latinoamericano Rosario. Editorial UCEL; 2006.

8. Minayo M. Pesquisa Social: Teoría, método y creatividad. Editora Vozes Ltda. Petrópolis Brasil; 1994.

9. Triviños A. Intriduçao à pesquisas en ciencias sociais: a pesquisa cualitativa emeducaçâo. Sâo Paolo: Editora Atlas; 1987.

10. Minayo M. El desafío del conocimiento: Investigación cualitativa en salud. Hucitec-Abasco San Paulo, Río de Janeiro; 1996.

11. Errazuriz A. Estudio descriptivo de la imagen del cuerpo en pacientes asmáticos evaluado a través del test de Rorschach [Tesis Licenciatura en Psicología]. Santiago de Chile: UDP; 2001.

12. Lillo J. Duelo y pérdida corporal. Informaciones Psiquiátricas. Barcelona; 2001, Num. 163

13. Torras E. Sobre l'esquema corporal i la identitat. Revista Catalana de Psicoanàlisi 1985; 2: 2

14. De Souza Y. O corpo como mediador da relação homem/mundo. In: Texto Contexto Enfermagem. UFSC: Filosofando na Enfermagem. Florianópolis; 1997.

15. Pereyra Z. Culturas hegemónicas en las prácticas corporales. La problemática de la imagen corporal [Internet]. Buenos Aires: 2002 [Acceso 11 de septiembre de 2010]. Disponible en: http://www.efdeportes.com

16. Calderón F. Programa de acción específico. Atención integral a la salud de las personas con discapacidad. Secretaría de Salud. Gobierno de los Estados Unidos Mexicanos. Presidencia de la República Mexicana 2007-2013.

17. Calderón F. Plan Nacional de Desarrollo. Gobierno de los Estados Unidos Mexicanos. Presidencia de la República Mexicana 2007-2013.

18. Calderón F. Plan Nacional de Salud. Gobierno de los Estados Unidos Mexicanos, Presidencia de la República Mexicana 2007-2013.

19. Herrera J. Plan Estatal de Desarrollo. Gobierno del Estado de Durango, México. 2011-2016.

20. Hernández S, Fernández C, Baptista L. Metodología de la investigación. Editorial McGraw-Hill, México; 2010. 